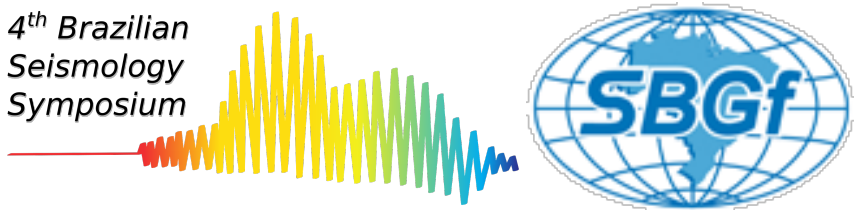

\title{
Tomography From Ambient Cross Correlation in Brazilian Southeastern Region
}

\author{
Fabio Dias ${ }^{1}$, Sergio Fontes ${ }^{1}$, Marco Antonio Thoaldo Romeiro². 1 Observatório Nacional. 2 Petrobras
}

\begin{abstract}
Copyright 2021, SBGf - Sociedade Brasileira de Geofísica.
This paper was prepared for presentation during the $17^{\text {th }}$ International Congress of the Brazilian Geophysical Society held in Rio de Janeiro, Brazil, 8-11 November 2021 (Online Event). Contents of this paper were reviewed by the Technical Committee of the $17^{\text {th }}$ International Congress of the Brazilian Geophysical Society and do not necessarily represent any position of the SBGf, its officers or members. Electronic reproduction or storage of any part of this paper for commercial purposes without the written consent of the Brazilian Geophysical Society is prohibited.
\end{abstract}

\begin{abstract}
Brazilian southeastern region has been poorly studied by seismic tomography. As an intraplate and aseismic region, the lack of strong events well recorded at seismograph stations jeopardizes the use of conventional tomography. In the literature, Brazilian southeast region appears in continental tomography inhibiting detailed study of this region. Aiming to better understand the geology of the region and along the continental margin, this present work uses the ambient cross-correlation noise tomography.
\end{abstract}

Data from stations appurtenant to Brazilian Seismographic Network and Brazilian Instrument Pool had been processed as follows. Firstly, the orientation accuracy for all stations through P-wave particle motion analyses of $\mathrm{mb}>6.0$ events from the IRIS catalog. In this stage, six stations were identified as ill-oriented. The wrong orientation was confirmed by field trips.

The seismograms were converted to velocity and merged in days; excluding those with gaps was longer than 20 seconds. The data were one-bit normalized to attenuate the influence of earthquakes during the correlation. All the process was performed to vertical and horizontals components. Vertical component from all stations was crosscorrelated among them as well as vertical components. After that step, horizontals components were rotated to radial and transversal according to the pairs of the stations.

The correlation-grams were stacked and the Love and Rayleigh group velocity surface wave dispersion was measured. The curves show dispersion between $7 \mathrm{~s}$ and $30 \mathrm{~s}$. Shear velocity models derived from the dispersions curves and preliminary results from tomography inversion show correlations with local geology: low velocity in sedimentary basins and high velocities in more cratonic regions. 